\title{
Antimicrobial Resistance Situation in SCANU of Faridpur Medical College Hospital, a Tertiary Level Hospital in Bangladesh
}

\author{
AFM Pervez ${ }^{1}, \mathrm{KH} \mathrm{Lee}{ }^{2}, \mathrm{~F}$ Islam $^{3}, \mathrm{MK} \operatorname{Hassan}^{4}, \mathrm{R} \mathrm{Biswas}^{5}$
}

\begin{abstract}
:
Considering the high risk of neonatal sepsis in low and middle-income countries, empirical antibiotic therapy is commonly employed in most cases to clinically suspected septic neonates without the aid of culture and antibiotic sensitivity report. Increasing antimicrobial resistance is posing a threat to these practices and urges the obligation for understanding the causative organisms and their changing resistance pattern at the local level. Aim of this study was to identify the pathogens responsible for neonatal sepsis and understand their current antimicrobial resistance pattern. This prospective study was undertaken in the Special Care Newborn Unit of the Faridpur Medical College Hospital from October 2017 to November 2018. Venous blood culture and antimicrobial susceptibility of 56 suspected neonatal sepsis cases were studied. Among the 56 clinically suspected cases $86 \%$ had culture positive isolates in the specimen. Predominant isolates were Klebsiella (42\%) and coagulase-negative staphylococci (25\%). Of all the identified bacteria, $88 \%$ were resistant to $\geq 3$ classes of antibiotics. Eighty-five percent of Klebsiella isolates were found to be carbapenem-resistant along with $100 \%$ of E. coli isolates and $95 \%$ of Klebsiella isolates had possible extended spectrum b -lactamase production. Seventy-five percent of Acinetobacter isolates were multidrug-resistant and $100 \%$ of coagulase-negative staphylococci were methicillin resistant. The array of causative organisms and their increasing resistance to commonly practiced antibiotics are alarming. It is urgent to develop strategies focusing on all healthcare levels to cease the spread of antimicrobial resistance in an effort to reduce the burden of neonatal sepsis.
\end{abstract}

Key words: Neonatal Sepsis, Antimicrobial Resistance.

\section{Introduction:}

Annually, an estimated 2.7 million neonates (0-28 days of life) die worldwide, and approximately $98 \%$ of these deaths occur in developing countries ${ }^{1-3}$. Among the various causes, neonatal sepsis is one of the main reasons for neonatal mortality and morbidity. Globally it accounts for nearly 2.1 million deaths every year ${ }^{4}$.

1. Abu Faisal Md Pervez, MBBS. MD, Assistant Professor (Neonatology) and Head of the Department, Department of Pediatrics, Faridpur Medical College, Faridpur, Bangladesh.

2. Kyu Han Lee, MPH, Ph.D., Postdoctoral Fellow, Department of Epidemiology, Johns Hopkins Bloomberg School of Public Health, Baltimore, USA.

3. Farzana Islam, MBBS, MD, MPH, Ph.D., Deputy Project Coordinator, Infectious Disease Division, International Centre for Diarrhoeal Disease Research, Bangladesh.

4. Md. Kamrul Hassan, MBBS. DCH, Junior consultant (Pediatrics), Faridpur Medical College Hospital, Faridpur, Bangladesh.

5. Rajib Biswas, MBBS, Project Research Physician, International Centre for Diarrhoeal Disease Research, Bangladesh.

Address of correspondence :

Abu Faisal Md Pervez, MBBS. MD, Assistant Professor (Neonatology) and Head of the Department, Department of Pediatrics, Faridpur Medical College. Mobile: +88-01712025076,

E-mail: afmpervez@gmail.com
However, resource-poor countries such as Sub-Saharan and South Asian countries bear the greatest burden of $\mathrm{it}^{5-7}$. Roughly 1 million deaths each year in the developing countries are attributable to infections acquired in neonatal period ${ }^{1,4,7,8}$.

Currently, in Bangladesh, the majority of births take place at home, and many of the newborns with sepsis do not come to medical attention ${ }^{9,10}$. In addition, most districts and community hospitals do not have facilities to perform blood cultures, and the diagnosis of neonatal sepsis is mostly done clinically ${ }^{11}$. As a result, estimating the burden of neonatal sepsis in Bangladesh is challenging. However, one recent population-based surveillance found $14.5 \%$ of newborns had infections in their first 9 days of life ${ }^{1}$.

With the advancement of the Neonatal Intensive Care Unit (NICU) and Special Care Newborn Unit (SCANU), the quality of care and the survival of the preterm, low birth weight infants have increased ${ }^{12}$. However, it has created its own sets of risks. Bacterial sepsis is a common scenario in NICU and SCANU particularly in preterm, low birth weight infants and the overall death rates from neonatal sepsis range from $2 \%$ to as high as $50 \%$ in some cases ${ }^{13-18}$. 
Considering the significant risk of infection in the newborn, empiric antimicrobial therapy is commonly employed, but the treatment of neonatal sepsis is threatened by the steady increase in the prevalence of antimicrobial resistance (AMR) 19-22. Although WHO recommends ampicillin and gentamicin combination for the treatment of neonatal sepsis, hospital-based data show an alarming rate of resistance to these drugs among common pathogens causing neonatal sepsis ${ }^{11,16,20,23-26}$. On the other hand, the spectrum of organisms responsible for sepsis changes with geographic regions. To formulate strategies to treat neonatal sepsis and halt the spread of antimicrobial resistance, region and center-specific knowledge about the common causative organisms, their changing patterns and antibiotic resistance status are essential $^{11,13,16,27-29}$.

This study was undertaken to determine the current distribution of infecting pathogens along with antibiotic sensitivity and resistance profile in a cohort of neonates diagnosed with neonatal sepsis at Faridpur Medical College Hospital, Bangladesh.

\section{Materials and methods:}

This prospective study was undertaken in the Special Care Newborn Unit (SCANU) of the Faridpur Medical College Hospital (FMCH), Bangladesh from October 2017 to November 2018. During this period, 56 suspected cases of neonatal sepsis were studied. The neonates were selected as septicemic based on clinical evaluations.

Venous blood was obtained from the selected patients with proper aseptic precautions and sent for culture and antibiotic susceptibility testing in the clinical microbiology laboratory of the International Centre for Diarrhoeal Disease Research, Bangladesh (icddr,b). Blood culture bottles were placed in the BacT/ALERT machine. If the results were positive, then the broth was sub-cultured. Isolated colonies were identified and antibacterial susceptibility was tested using the VITEK2 system.

Descriptive analysis was performed using STATA 15 (StataCorp. College Station, TX).

MDR (Multi Drug Resistant) was defined as resistant to three or more classes of antibiotics. ESBL (Extended Spectrum Beta-Lactamase) was defined only based on resistance to ceftazidime or ceftriaxone, confirmatory tests using tests in combination with clavulanic acid was needed but not done.

\section{Result:}

The predominant isolates were Klebsiella 20 (41.7\%) and coagulase-negative staphylococci (CoNS) 12 $(25.0 \%)$. The isolates of Acinetobacter 4 (8.3\%), E. coli $4(8.3 \%)$, gram-positive bacillus (GPB) 3 (6.3\%), Enterobacter 2 (4.2\%), Enterococcus 1 (2.1\%), Pseudomonas 1 (2.1\%) and Streptococcus 1 (2.1\%) were also observed but in lesser proportions (Table I).

\begin{tabular}{lll}
\multicolumn{2}{l}{ Table I: Identified bacterial* isolates $(\mathrm{n}=48)$} \\
\hline Name of the organism & $\begin{array}{l}\text { Number } \\
\text { of isolates }\end{array}$ & Percentage \\
\hline Klebsiella & 20 & $42 \%$ \\
CoNS $^{\mathrm{a}}$ & 12 & $25 \%$ \\
Acinetobacter & 4 & $8 \%$ \\
E. coli & 4 & $8 \%$ \\
GPB & 3 & $6 \%$ \\
Enterobacter & 2 & $4 \%$ \\
Enterococcus & 1 & $2 \%$ \\
Pseudomonas & 1 & $2 \%$ \\
Streptococcus & 1 & $2 \%$ \\
\hline
\end{tabular}

${ }^{\mathrm{a} C o N S}$ : coagulase-negative staphylococci

${ }^{\mathrm{b}} \mathrm{GPB}$ : Gram-positive bacillus

*Level of taxonomic classification varies by isolates. Some isolates were grouped under CoNS for convenience.

Among the identified bacterial isolates, 42 (87.5\%) were resistant to $\geq 3$ classes of antibiotics. Among them $19(95 \%)$ Klebsiella isolates were resistant to $\geq 3$ classes of antibiotics. All isolates of CoNS, Acinetobacter, E. coli, Enterococcus, and Streptococcus were resistant to $\geq 3$ classes of antibiotics as well. All the GPB isolates were found to be sensitive to all of the antibiotic classes (Table II).

Table II: Number of antibiotic classes with resistance

\begin{tabular}{llllll}
\hline $\begin{array}{l}\text { Name of the } \\
\text { organism }\end{array}$ & \multicolumn{6}{l}{ Number of antibiotic classes } & Total \\
\hline Klebsiella & $0(0 \%)$ & $1(5 \%)$ & $0(0 \%)$ & $19(95 \%)$ & 20 \\
CoNS & $0(0 \%)$ & $0(0 \%)$ & $0(0 \%)$ & $12(100 \%)$ & 12 \\
Acinetobacter & $0(0 \%)$ & $0(0 \%)$ & $0(0 \%)$ & $4(100 \%)$ & 4 \\
E. coli & $0(0 \%)$ & $0(0 \%)$ & $0(0 \%)$ & $4(100 \%)$ & 4 \\
GPB & $3(100 \%)$ & $0(0 \%)$ & $0(0 \%)$ & $0(0 \%)$ & 3 \\
Enterobacter & $0(0 \%)$ & $1(50 \%)$ & $0(0 \%)$ & $1(50 \%)$ & 2 \\
Enterococcus & $0(0 \%)$ & $0(0 \%)$ & $0(0 \%)$ & $1(100 \%)$ & 1 \\
Pseudomonas & $0(0 \%)$ & $0(0 \%)$ & $0(0 \%)$ & $1(100 \%)$ & 1 \\
Streptococcus & $0(0 \%)$ & $0(0 \%)$ & $1(100 \%)$ & $0(0 \%)$ & 1 \\
Total & $\mathbf{3 ( 6 \% )}$ & $\mathbf{2 ( 4 \% )}$ & $\mathbf{1}(\mathbf{2} \%)$ & $\mathbf{4 2 ( 8 8 \% )}$ & $\mathbf{4 8}$
\end{tabular}


Among the Enterobacteriaceae isolates, carbapenem resistance was found to some extents in all isolates; Klebsiella 17 (85\%), Enterobacter 1 (50\%), and E. coli $1(25 \%)$. Resistance to colistin was found only in Klebsiella $6(30 \%)$, and all which were also resistant to carbapenem. Based on resistance to ceftazidime or ceftriaxone, all of the E. coli isolates $4(100 \%)$ were found to be producing extended spectrum b-lactamase (ESBL). Nineteen (95\%) Klebsiella isolates and 1 $(50 \%)$ Enterobacter isolate had possible ESBL production (Table III).

Table III: AMR among Enterobacteriaceae isolates

\begin{tabular}{llll}
\hline $\begin{array}{l}\text { Antimicrobial } \\
\text { agents and ESBL } \\
\text { production }\end{array}$ & Klebsiella & Enterobacter & E. coli \\
Carbapenem & $17(85 \%)$ & $1(50 \%)$ & $1(25 \%)$ \\
Colistin & $6^{*}(30 \%)$ & $0(0 \%)$ & $0(0 \%)$ \\
$\begin{array}{l}\text { Possible ESBL } \\
\text { production** }\end{array}$ & $19(95 \%)$ & $1(50 \%)$ & $4(100 \%)$ \\
& & &
\end{tabular}

*All were also carbapenem-resistant

**Only based on resistance to ceftazidime or ceftriaxone. Most were resistant to both.

When carbapenem resistant Klebsiella isolates were plotted over the study time, one or more isolates resistant to carbapenem were found in 9 occasions whereas isolates not resistant to carbapenem were found in 3 occasions. Most of the carbapenem-resistant Klebsiella isolates were found between the $28^{\text {th }}$ to $37^{\text {th }}$ weeks of the study period (Figure I).

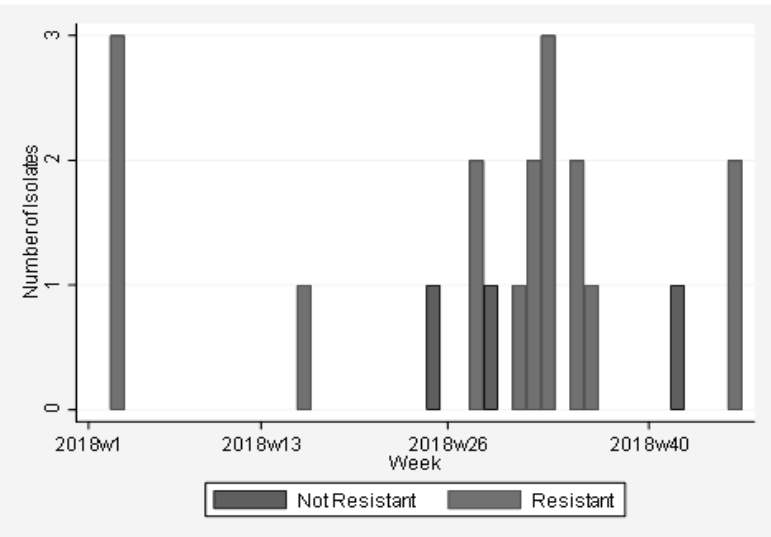

Figure I: Carbapenem-resistant Klebsiella isolates over time
Over the study period, the two most common Klebsiella antibiogram profiles were also observed. Between the $28^{\text {th }}$ to $34^{\text {th }}$ weeks, a group of Klebsiella was found to be resistant to all antibiotic groups (Figure II).

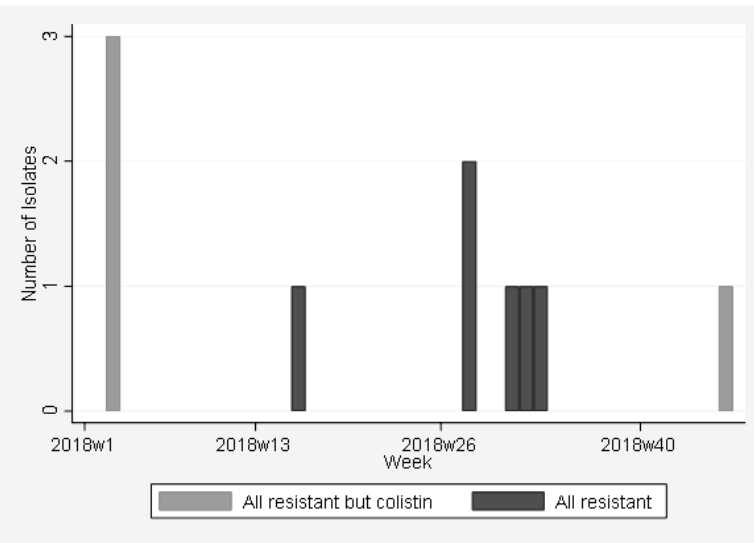

Figure II: Two most common Klebsiella antibiogram profiles* over time

*Based on antibiogram using sensitivity to amikacin, ampicillin, cefepime, ceftazidime, ceftriaxone, cefuroxime, ciprofloxacin, colistin, cotrimoxazole, gentamicin, imipenem, meropenem, and piperacillin/tazobactam. All other antibiogram profiles were unique to one isolate or shared by one other isolate.

Among the 4 Acinetobacter isolates, 3 (75\%) were found to be multidrug-resistant (MDR) according to the CDC definition ${ }^{30}$. Among the others, 1 (25\%) was colistin resistant and $1(25 \%)$ was tigecycline resistant (Table V).

Table V: AMR among Acinetobacter isolates

\begin{tabular}{lll}
\hline Antibiotic resistance & Number $(\mathbf{N}=4)$ & Percentage \\
\hline MDR & 3 & $75 \%$ \\
Colistin-resistant & 1 & $25 \%$ \\
Tigecycline-resistant & 1 & $25 \%$ \\
\hline
\end{tabular}

During the study period, MDR Acinetobacter isolates were found roughly at the beginning, middle, and ending of the study (Figure III). 


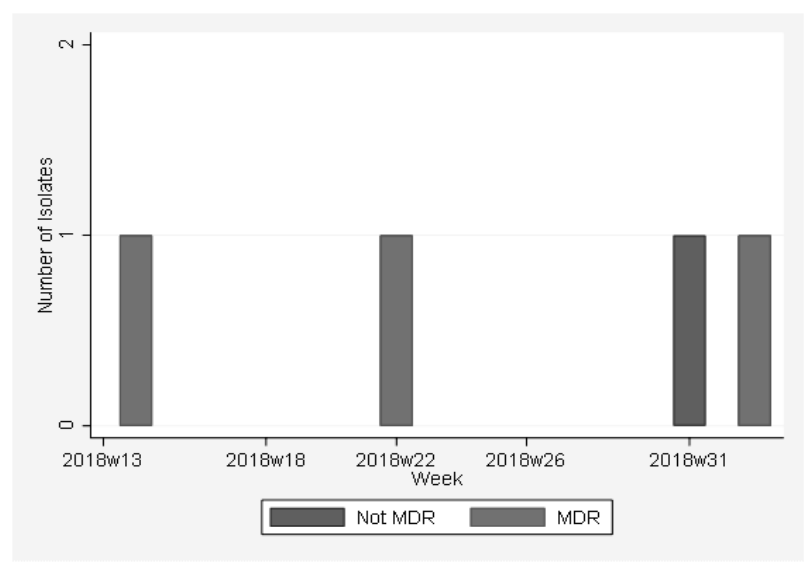

Figure III. MDR Acinetobacter isolates over time

Among the other bacteria, $12(100 \%)$ coagulasenegative staphylococci were methicillin-resistant and none of the (0\%) Enterococcus isolates was resistant to vancomycin (VRE).

\section{Discussion:}

Among the 56 suspected neonatal sepsis blood specimens that we cultured, $86 \%$ of them had various types of bacterial isolates. Only $14 \%$ of the clinically suspected septic neonates had no bacteria detected in their blood culture. Although the majority of neonates with clinically diagnosed sepsis had proven isolated organisms in their blood, all of them, including those without detectable bacterial isolates received empiric antibiotic therapy.

Of the different isolated organisms, Klebsiella, CoNS, Acinetobacter, and E. coli were found to be the most dominant and contributed to neonatal sepsis in more than $75 \%$ cases collectively. Klebsiella alone was the responsible organism for approximately $40 \%$ of the septic neonates.

Many studies reported that CoNS are the most common organisms associated with neonatal sepsis, but those were found in high-income countries and was mostly in late onset neonatal sepsis ${ }^{17,31-35}$. However, we found CoNS (24\%) to be the second most common organisms and Klebsiella to be the commonest. Our findings coincide with studies done by Genatra et al., Karunasekera et al., Tallur et al., Teresa et al. ${ }^{36-38}$. that looked into the neonatal infection pattern in low- and middle-income countries; where they found Klebsiella as the predominant pathogen responsible for nearly $25 \%$ of all cases of neonatal sepsis ${ }^{11}$.
In our study, we found only 1 isolate of Pseudomonas and 1 of Streptococcus. These findings differ from prior studies where they found a higher association of these organisms with neonatal sepsis ${ }^{5,11,13,23,39}$. This may be due to geographic region-specific dominance of specific organisms or simply may be due to difference in sampling approach. However, some studies suggest that despite a high rate of colonization, the attack rate of Staphylococcus aureus infections are relatively as low as $2 \%{ }^{16,40}$.

We found no case of sepsis with group B streptococcus which is more common in early onset neonatal sepsis in high income countries but not in low- and middleincome countries ${ }^{41}$.

Colonization and subsequent infection with strains of antibiotic resistant bacteria has become a major concern in hospitalized neonates with a greater risk in SouthEast Asian countries, where the rate of antibiotic resistance is higher ${ }^{25}$.

In our study, among the Enterobacteriaceae isolates, Klebsiella was the commonest. Increasing antibiotic resistance among Enterobacteriaceae isolates has raised a major concern as sepsis with these organisms are associated with considerable morbidity and mortality of the neonates ${ }^{16,18,42,43}$. Among the members of the Enterobacteriaceae family that we found, resistance to carbapenem was found in $85 \%$ of Klebsiella isolates, $50 \%$ of Enterobacter isolates, and $25 \%$ of E. coli isolates. Moreover, $30 \%$ of the Klebsiella isolates were colistin-resistant, all of which were also resistant to carbapenem. Nearly all of the E. coli and Klebsiella isolates and half of the Enterobacter isolates had possible ESBL production. Such a picture of resistance even to newer generations of antibiotics is a great threat to the upcoming future. Recent studies agree that members of Enterobacteriaceae family are most often resistant to at least one of the classical parenteral antibiotics used in neonates ${ }^{16,44,45}$.

All of the CoNS isolates that we found were resistant to $\geq 3$ antibiotic classes. It is an alarming situation as they are resistant to the routine antibiotics that are used to treat neonates and often require vancomycin or other antibiotics for adequate therapy. This similar resistance pattern is being found in a growing number of studies $^{17,20}$.

Infection with such organisms presents a serious challenge to clinicians as the antibiotic choice for treating such infection is limited. In such cases, associated mortality has also been found to be higher ${ }^{17}$. 
Of the 4 Acinetobacter isolates that we found, $75 \%$ were MDR. One of the isolates $(25 \%)$ was colistinresistant and another one (25\%) was tigecyclineresistant. Studies done in other parts of Asia have found $15 \%$ to as high as $22 \%$ of all tested antibiotic-resistant isolates of Acinetobacter ${ }^{5,39}$.

Also, we found such resistant isolates of Klebsiella and Acinetobacter were almost evenly at different times throughout our study period.

Over time, the evolution of hyper virulent clones of bacteria causing neonatal sepsis will become an increasing problem unless controlled effectively ${ }^{12}$.

With such an antibiotic resistance pattern and the emergence of MDR bacteria will pose a great challenge to the recommended empiric use of ampicillin and gentamycin combination for the treatment of neonatal sepsis.

\section{Conclusion:}

Increasing antimicrobial resistant pattern is often leaving us with a few antibiotics as a safe resort for treating highly-resistant virulent organisms. Strategies and guidelines at the local level need to be formulated to halt the global spread of antimicrobial resistance.

\section{Acknowledgment:}

Child Health and Mortality Prevention Surveillance (CHAMPS), icddr,b.

\section{References :}

1. Mitra DK, Mullany LC, Harrison M, Mannan I, Shah R, Begum N, et al. Incidence and risk factors of neonatal infections in a rural Bangladeshi population: a community-based prospective study. J Health Popul Nutr. 2018 Mar 9;37(1):6.

2. Liu L, Hill K, Oza S, Hogan D, Chu Y, Cousens S, et al. Levels and Causes of Mortality under Age Five Years. Dis Control Priorities, Third Ed (Volume 2) Reprod Matern Newborn, Child Heal. 2016;71-83.

3. Oestergaard MZ, Inoue M, Yoshida S, Mahanani WR, Gore FM, Cousens S, et al. Neonatal mortality levels for 193 countries in 2009 with trends since 1990: A systematic analysis of progress, projections, and priorities. PLoS Medicine.2011Aug;8(8) :e1001080.

4. Oza S, Lawn JE, Hogan DR, Mathers C, Cousens SN. Neonatal cause-of-death estimates for the early and late neonatal periods for 194 countries: 2000-2013. Bull World Health Organ. 2015;93(1):19-28

5. Tiskumara R, Fakharee SH, Liu CQ, Nuntnarumit P, Lui KM, Hammoud M, et al. Neonatal infections in Asia. Arch Dis Child Fetal Neonatal Ed. 2009 Mar;94(2).F144-8.

6. Bryce J, Boschi-Pinto C, Shibuya K, Black RE. WHO estimates of the causes of death in children. Lancet. 2005 Mar 26;365(9465):1147-52.
7. Black RE, Cousens S, Johnson HL, Lawn JE, Rudan I, Bassani DG, et al. Global, regional, and national causes of child mortality in 2008: a systematic analysis. Lancet. 2010;375(9730):1969-87.

8. Bang AT, Paul VK, Reddy HM, Baitule SB. Why do neonates die in rural Gadchiroli, India? (Part I): Primary causes of death assigned by neonatologist based on prospectively observed records. J Perinatol. 2005;25(SUPPL. 1):S29-34.

9. Thaver D, Zaidi AKM. Burden of neonatal infections in developing countries: A review of evidence from community-based studies. Pediatr Infect Dis J. 2009;28(SUPPL. 1):S3-9.

10. Masud Ahmed S, Bushra Binte Alam J, Bank Iqbal Anwar W, Begum T, Bank Rumana Huque W, Khan JA, et al. Asia Pacific Observatory on Public Health Systems and Policies. Bangladesh Health System Review, Health Systems in Transition. 2015; 3.

11. Ganatra HA, Zaidi AKM. Neonatal Infections in the Developing World. Seminars in Perinatology. 2010Dec;34(6): 416-25.

12. Cimolai N. Staphylococcus aureus outbreaks among newborns: New frontiers in an old dilemma. American Journal of Perinatology. 2003Apr;20(3):125-36

13. Bizzarro MJ, Raskind C, Baltimore RS, Gallagher PG. Seventyfive years of neonatal sepsis at Yale: 1928-2003. Pediatrics. 2005 Sep;116(3):595-602

14. Stoll BJ, Hansen N. Infections in VLBW infants: Studies from the NICHD Neonatal Research Network. Semin Perinatol. 2003;27(4):293-301.

15. Stoll BJ, Hansen NI, Adams-Chapman I, Fanaroff AA, Hintz SR, Vohr B, et al. Neurodevelopmental and growth impairment among extremely low-birth-weight infants with neonatal infection. J Am Med Assoc. 2004 Nov 17;292(19):2357-65.

16. Bizzarro MJ, Gallagher PG. Antibiotic-Resistant Organisms in the Neonatal Intensive Care Unit. Seminars in Perinatology. 2007Feb;31(1):26-32.

17. Stoll BJ, Hansen N, Fanaroff AA, Wright LL, Carlo WA, Ehrenkranz RA, et al. Late-onset sepsis in very low birth weight neonates: The experience of the NICHD Neonatal Research Network. Pediatrics. 2002;110(2 I):285-91

18. Stoll BJ, Hansen N, Fanaroff AA, Wright LL, Carlo WA, Ehrenkranz RA, et al. Changes in pathogens causing early-onset sepsis in very-low-birth-weight infants. N Engl J Med. 2002 Jul 25;347(4):240-7.

19. Vergnano S, Sharland M, Kazembe P, Mwansambo C, Heath PT Neonatal sepsis: An international perspective. Arch Dis Child Fetal Neonatal Ed. 2005;90(3)

20. Doare K Le, Bielicki J, Heath PT, Sharland M. Systematic review of antibiotic resistance rates among gram-negative bacteria in children with sepsis in resource-limited Countries. J Pediatric Infect Dis Soc. 2015 Mar;4(1):11-20.

21. Kapoor L, Randhawa VS, Deb M. Microbiological profile of neonatal septicemia in a pediatric care hospital in Delhi. J Commun Dis. 2005;37(3):227-32.

22. Waheed M, Laeeq A, Maqbool S. The etiology of neonatal sepsis and patterns of antibiotic resistance. J Coll Physicians Surg Pakistan. 2003;13(8):449-52

23. Friedman S, Shah V, Ohlsson A, Matlow AG. Neonatal Escherichia coli infections: Concerns regarding resistance to current therapy. Acta Paediatr Int J Paediatr. 2000;89(6):686-9.

24. Thaver D, Ali SA, Zaidi AKM. Antimicrobial resistance among neonatal pathogens in developing countries. Pediatr Infect Dis J. 2009Jan;28(SUPPL. 1):19-21. 
25. Zaidi AKM, Huskins WC, Thaver D, Bhutta ZA, Abbas Z, Goldmann DA. Hospital-acquired neonatal infections in developing countries. Lancet. 2005;365(9465):1175-88

26. Downie L, Armiento R, Subhi R, Kelly J, Clifford V, Duke T. Community-acquired neonatal and infant sepsis in developing countries: Efficacy of WHO's currently recommended antibiotics Systematic review and meta-analysis. Arch Dis Child. 2013 Feb;98(2):146-54.

27. Philip AGS. The changing face of neonatal infection: Experience at a regional medical center. Pediatr Infect Dis J. 1994;13(12):1098-102.

28. Leibovitz E, Flidel-Rimon O, Juster-Reicher A, Amitay M, Miskin A, Barak Y, et al. Sepsis at a neonatal intensive care unit: a fouryear retrospective study (1989-1992). Isr J Med Sci. 1997 Nov;33(11):734-8

29. Cordero L, Sananes M, Ayers LW. Bloodstream Infections in Neonatal Intensive-Care Unit: 12 Years' Experience With an Antibiotic Control Program. Infect Control Hosp Epidemiol. 1999 Apr;20(4):242-6.

30. CDC. Multidrug-Resistant Organism \& Clostridioides difficile Infection (MDRO/CDI) Module. 2018.

31. Berger A, Salzer HR, Weninger M, Sageder B, Aspöck C Septicaemia in an Austrian neonatal intensive care unit: A 7-year analysis. Acta Paediatr Int J Paediatr. 1998 Jan 2;87(10):1066-9.

32. Stoll BJ, Gordon T, Korones SB, Shankaran S, Tyson JE, Bauer CR, et al. Late-onset sepsis in very low birth weight neonates: A report from the national institute of child health and human development neonatal research network. J Pediatr. 1996;129(1):63-71.

33. Isaacs D, Barfield C, Clothier T, Darlow B, Diplock R, Ehrlich J, et al. Late-onset infections of infants in neonatal units. J Paediatr Child Health. 1996 Apr;32(2):158-61.

34. Gray JE, Richardson DK, McCormick MC, Goldmann DA. Coagulase-negative staphylococcal bacteremia among very low birth weight infants: Relation to admission illness severity, resource use, and outcome. Pediatrics. 1995;95(2):225-30.

35. Isaacs D. A ten year, multicentre study of coagulase negative staphylococcal infections in Australasian neonatal units. Arch Dis Child Fetal Neonatal Ed. 2003 Mar;88(2):89-93.

36. Teresa Moreno M, Vargas S, Poveda R, Sáezllorens X. Neonatal sepsis and meningitis in a developing latin american country. Pediatr Infect Dis. 1994;13(6):516-20.

37. Tallur SS, Kasturi AV, Nadgir SD, Krishna BV. Clinicobacteriological study of neonatal septicemia in Hubli. Indian Pediatr. 2000;67(3):169-74.

38. Karunasekera KA, Pathirana D. A preliminary study on neonata septicaemia in a tertiary referral hospital paediatric unit. Ceylon Med J. 1999;44(2):81-6

39. Joshi SG, Ghole VS, Niphadkar KB. Neonatal gram-negative bacteremia. Indian J Pediatr. 2000;67(1):27-32

40. Gooch JJ, Britt EM. Staphylococcus aureus Colonization and Infection in Newborn Nursery Patients. Am J Dis Child. 1978;132(9):893-6.

41. Daoud AS, Abuekteish F, Obeidat A, El-Nassir Z, Al-Rimawi H. The changing face of neonatal septicaemia. Ann Trop Paediatr. 1995;15(1):93-6.
42. Jones B, Peake K, Morris AJ, McCowan LM, Battin MR. Escherichia coli: A growing problem in early onset neonatal sepsis. Australian and New Zealand Journal of Obstetrics and Gynaecology. 2004Dec;44(6): 558-61.

43. Schuchat A, Zywicki SS, Dinsmoor MJ, Mercer B, Romaguera J, O'Sullivan MJ, et al. Risk factors and opportunities for prevention of early-onset neonatal sepsis: A multicenter case-control study. Pediatrics. 2000;105(1 Pt 1):21-6.

44. Waterer GW, Wunderink RG. Increasing threat of Gram-negative bacteria. Crit Care Med. 2001;29(4 SUPPL.):N75-80.

45. Shah A, Mulla S, Revdiwala S. Neonatal sepsis: High antibiotic resistance of the bacterial pathogens in a neonatal intensive care unit of a tertiary Care hospital. J Clin Neonatol. 2012;1(2):72. 